\title{
Soft Tissue Chondroma: A Case Report and Literature Review
}

\author{
Moosa Bahnassy, ${ }^{1}$ Hala Abdul-Khalik ${ }^{2}$
}

\section{Abstract}

Extra skeletal soft tissue chondroma is a very rare, slow progressing, benign tumor. It has a specific tendency for hands and feet. It can sometimes be misdiagnosed as a synovial cyst or a more serious condition such as synovial sarcoma. Moreover, it can exhibit worrying radiologic and histological features mimicking chondrosarcomas. This study presents a very rare case of soft tissue chondroma of the foot.

A 42 year old Egyptian male patient was presented with a slow developing swelling on the left foot for 7 years duration. The patient was examined thoroughly and proved to have a hard, fixed, nontender swelling of approximately $4 \times 2.5 \mathrm{~cm}$ in size with well defined borders involving the dorsal aspect of the proximal left foot. The patient was investigated using the following techniques; plain $\mathrm{X}$-ray, MRI, and FNAC of the swelling which gave an impression of a benign chondroma arising from the soft tissues of the dorsum of the left foot. The patient felt pain while walking and wearing shoes, and was therefore scheduled for excision of the mass under general anesthesia and limb exsanguination at Ghayathi hospital. Postoperative histopathological assessment identified a soft tissue chondroma.

There is limited literature and limited cases reported of soft tissue chondroma. So far, this is the second case of its kind to ever be reported at Ghayathi hospital.

From the ${ }^{1}$ Department of Surgery, Ghayathi Hospital, Abu Dhabi, UAE, ${ }^{2}$ Department of Histopathology, Madint Zayed Hospital, UAE.

Received: 22 Jul 2009

Accepted: 01 Sep 2009

Address correspondence and reprint requests to: Mousa Bahnassy, Department of Surgery, Ghayathi Hospital, Abu Dhabi.

E-mail:mousagalal@hotmail.com

Bahnassy M, et al. OMJ. 24, 296-299 (2009); doi:10.5001/omj.2009.60

\section{Introduction}

oft tissue chondroma is a rare benign tumor which has a tendency to occur in the hands and feet. It affects both sexes equally and mainly occurs in patients aged $30-60$ years. ${ }^{1,2,3}$ Repeated micro trauma may be an initiating factor. It presents as a slowly growing mass, most commonly in the hands and feet. ${ }^{1,4}$

It should be differentiated from benign tumors like ganglion cyst, myositis ossificans, pseudomalignant osseous tumor, ossifying fibromyxoid tumor, synovial chondromatosis, osteochondroma, or a malignant tumor like chondrosarcoma, extra skeletal osteosarcoma and synovial sarcoma, 5,6 Diagnostic errors can be avoided if any soft tissue lesion that cannot be diagnosed is regarded as potentially malignant until proven otherwise ${ }^{6,7}$

It arises from the synovial sheath of the long tendons, the paratendinous soft tissues or the para-articular tissues. ${ }^{5,8,9}$

Extra-skeletal chondromas are composed of hyaline cartilage with focal calcification and can show worrying radiologic and histological pictures simulating chondrosarcoma ${ }^{10,11}$

MRI is the method of choice in the evaluation of this rare clinical entity. This tumor rarely evolves into a malignant tumor., ${ }^{9,12}$

The clinical, radiological and cytological triad is important for the correct diagnosis of soft tissue chondroma despite worrying cell atypia ${ }^{14,15}$

Positive diagnosis can only be provided by the histopathological examination. Surgical treatment is the only successful solution but recurrence is not uncommon. ${ }^{11,14,15}$

\section{Case report}

A 42 year old Egyptian male was presented to the surgical outpatient department (OPD) at Ghayathi hospital with a slowly progressive mass in the dorsum of his left foot of around 7 years duration. Initially, the swelling was painless until 4 months before he attended the OPD, when he started to feel increasing pain in his left foot on walking for long distances. The pain increased in intensity on wearing shoes. The patient had a mild tingling sensation in the dorsum of the first web space associated with mild difficulty in upward stretching of his left big toe. However, there was no history of trauma. Furthermore, family history and personal history were irrelevant. General clinical assessment was normal.

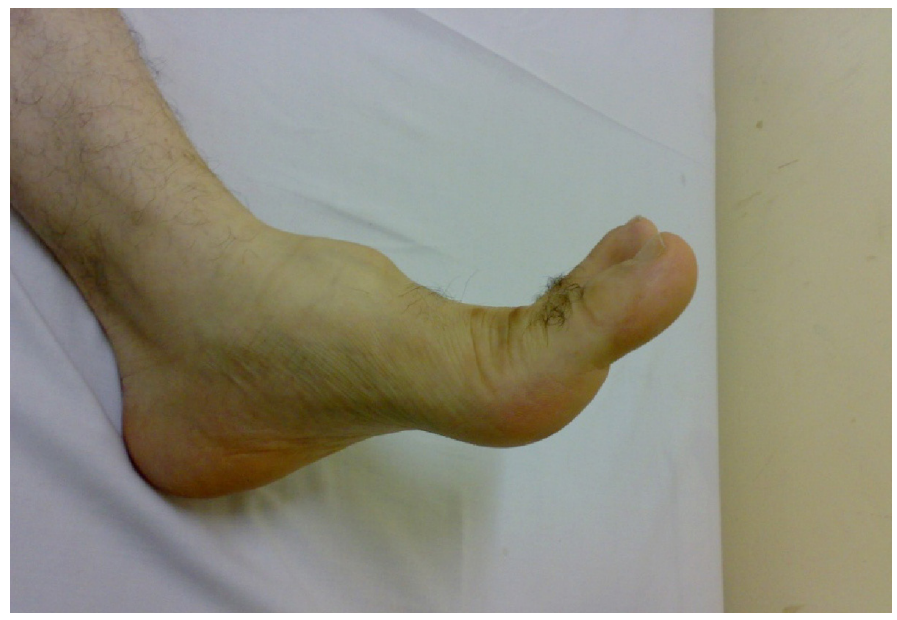

Figure 1: Hard, lobulated, nontender swelling on the left foot. 
Locally, there was a hard, fixed, lobulated, nontender swelling on the dorsal aspect of the left foot. The swelling was $4 \times 2 \mathrm{~cm}$ in size with well-defined borders. It was not attached to the overlying skin (Fig. 1). Distal circulation was normal but the dorsalis pedis was palpated with difficulty. Neurological examination showed mild hypoesthesia over the dorsum of the first web space.

Hematological and biochemical tests including CBC, ESR, LFTs, KFTs, and FBS were within normal limits.

An X-ray of the antero-posterior, lateral and oblique views showed a normal bony skeleton of the foot with no evidence of calcifications (Fig. 2).

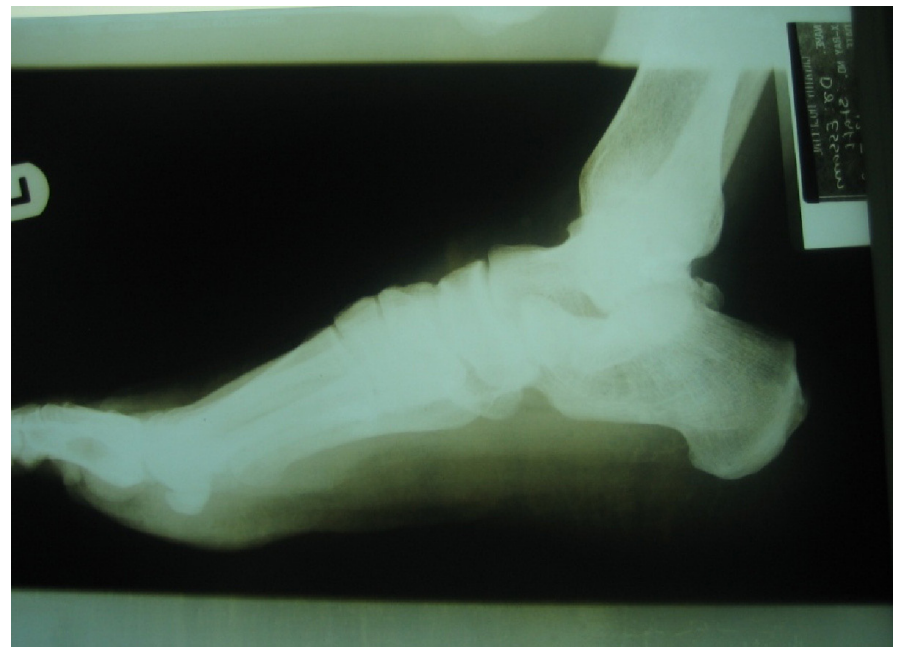

Figure 2: An X-ray of the antero-posterior.

Ultrasound examination of the mass clarified a well defined soft tissue mass of around $3 \times 2 \times 2 \mathrm{~cm}$ in size. The mass had a thickened wall and a hypo-echoic center and it contained one or more hyper-echoic minute foci (Fig. 3).

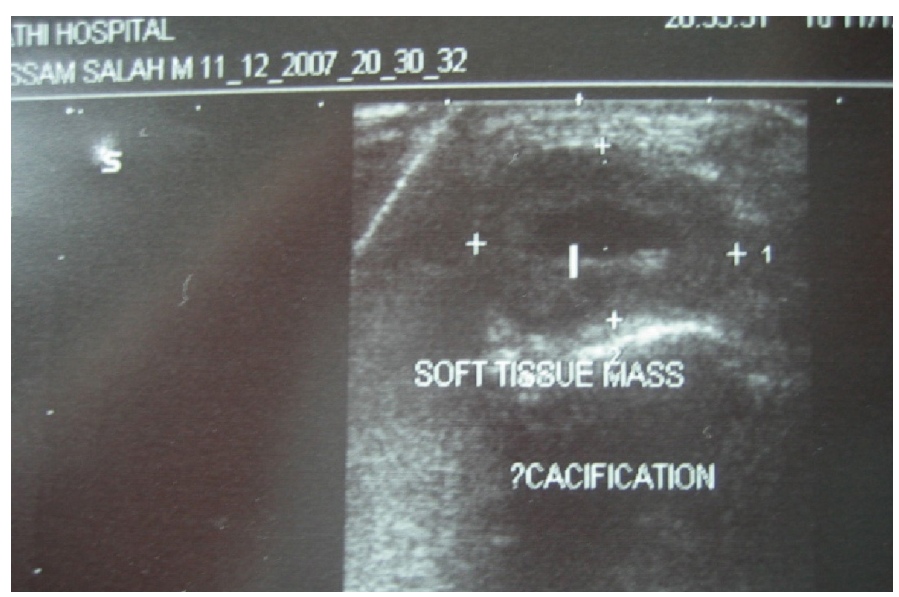

Figure 3: Ultrasound examination of the mass.

MRI of the left foot before and after IV contrast showed a well circumscribed soft tissue mass with hypo-intense central zone.
The mass was $3.4 \times 2.3 \mathrm{~cm}$ in size with a lobulated surface. The mass was related to the extensor hallucis longus tendon and lying directly over the intermediate and medial cuneiform bones. The periosteum of the bones was intact.

Fine needle aspiration cytology (FNAC) of the mass revealed chondrocytes in a cartilaginous matrix with mild insignificant cellular atypia. The overall picture was suggestive of soft tissue chondroma (Fig. 4).

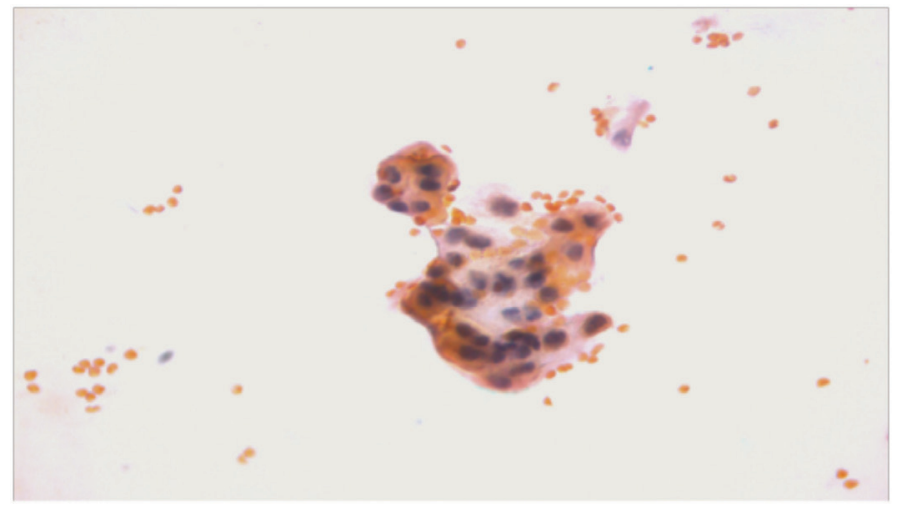

Figure 4: FNAC of the Mass.

Since the patient was suffering from left foot pain with progressive inability to wear his left shoe, he was scheduled for excisional biopsy of the mass under GA with exsanguination of the limb using A/K pneumatic tourniquet.

Intraoperatively, the mass was found to be hard, lobulated, grayish white situated under the inferior extensor retinaculum, in close proximity to the lateral surface of the extensor hallucis longus and close to the dorsal periosteum of the intermediate cuneiform bone.

The swelling was excised completely (Figs. $5 \& 6$ ). The patient had a smooth post-operative course and was discharged from the hospital on the second post-operative day in good general condition.

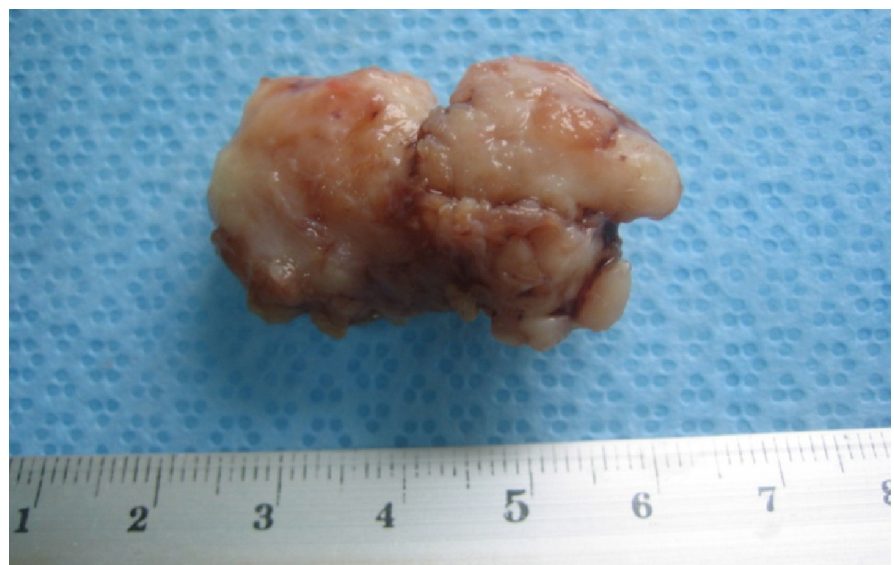

Figure 5: Excised contents of the swelling. 


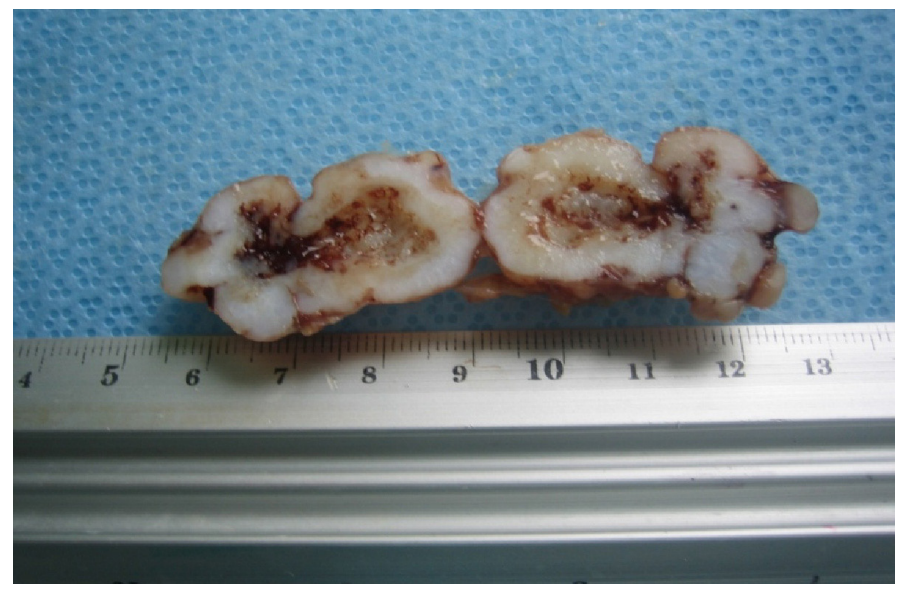

Figure 6: Disection of the Mass.

Histological assessment of the resected specimen confirmed a soft tissue chondroma characterized by chondrocytes in hyaline matrix with mild focal cellular atypia as shown in Fig. 7.

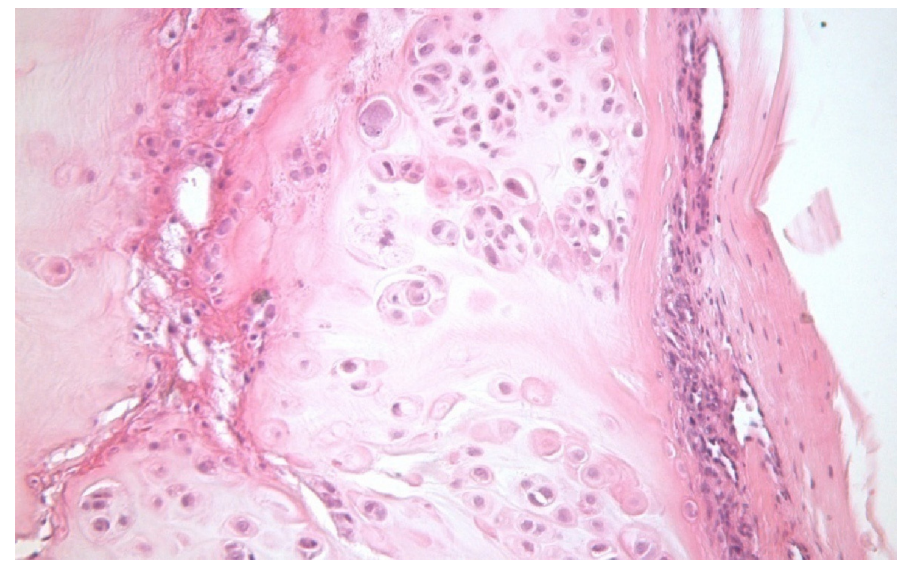

Figure 7: Histological assessment of the specimen

\section{Discussion}

Soft tissue chondroma is a rare clinical entity. It has the following characteristic features:

1) Benign clinical course.

2) Not attached to the underlying bone.

3) Slow growth.

4) The absence of age and sex predominance

5) The histological picture. ${ }^{14,15}$

The patient had developed the tumor over a 7 year course. He remained asymptomatic throughout, except for the last 4 months before surgery, when he developed increasing pain on walking and on wearing shoes. The mass was positioned completely within the soft tissues and was not attached to the underlying bone at all. Clinical examination revealed a fixed mass; this is because the tumor was lying under the inferior extensor retinaculum. Histological assessment of the tumor showed features of benign chondroma.

Soft tissue tumors should be investigated carefully if the clinical diagnosis is a matter of great concern. The best radiologic modality is MRI, as it can define the extent, the contour, the shape and the intensity of the tumor in addition to its relation to the surrounding structures and calcifications, if any., 10, 11

The patient had undergone an MRI to ascertain the lesion from other soft tissue masses to some extent. Furthermore, it helped to determine the exact location, extent of the mass and its relation to surrounding structures.

FNAC of soft tissue masses is not widely practiced for suspected soft tissue tumors. Only one case has ever been reported in the literature to have undergone FNAC for soft tissue chondroma to determine the diagnosis preoperatively. ${ }^{9}, 13$

Preoperative cytological assessment was performed for the patient to ascertain the diagnosis and decide the proper plan of management of the tumor. The assessment provided a preliminary diagnosis of soft tissue chondroma. However, the absence of significant cellular atypia and abnormal mitotic figures relieved the concern of malignancy.

Postoperative histological examination of the excised specimen was the best diagnostic modality to give the final diagnosis and determine the prognosis. Soft tissue chondroma, once excised adequately, would rarely recur. Thus, recurrence is not exceptional., ${ }^{7,14}$ One year after the surgery, the patient was doing well with no evidence of recurrence.

\section{Conclusion}

Overall, soft tissue chondroma is a very rare benign tumor most commonly affecting the extremities like the hands and feet. It has a slowly progressive benign course. It can be misdiagnosed as a malignant tumor based on its clinical features unless radiology and cyto/histology of the tumor of the affected part are performed.

Generally, if the tumour is excised completely, it rarely recurs.

\section{Acknowledgements}

I present my great regards and dedicate this article to my wife Mrs. Sawsan T. Deghidy for reviewing and typing this report.

\section{References}

1. Khedhaier A, Maalla R, Ennouri K, Regaya N. Soft tissues chondromas of the hand: a report of five cases. Acta Orthop Belg 2007 Aug;73(4):458-461.

2. Rizzello G, Franceschi F, Meloni MC, Cristi E, Barnaba SA, Rabitti C, et al. Para-articular osteochondroma of the knee. Arthroscopy 2007 Aug;23(8):910, e1-e4. 
3. Papagelopoulos PJ, Savvidou OD, Mavrogenis AF, Chloros GD, Papaparaskeva KT, Soucacos PN. Extraskeletal chondroma of the foot. Joint Bone Spine 2007 May;74(3):285-288.

4. Gentles C, Perin J, Berrey H, Griffiths HJ. Radiologic case study. Soft-tissue chondroma. Orthopedics 2007 Mar;30(3):180, 241-243.

5. Oliva F, Venanzi R, Fratoni S, Maffulli N. Chondroma of the subcutaneous bursa of the Achilles tendon. Bull Hosp Jt Dis 2005;63(1-2):24-26.

6. Singh P, Mathur SK, Kunda ZS. Extra skeletal chondroma of the hand- a case report. Indian J Pathol Microbiol 2005;48:306-308.

7. Ohtsuka H. Chondrolipoma of the popliteal fossa and Japanese reports. J Dermatol 2006 Mar;33(3):202-206.

8. Varras M, Akrivis Ch, Tsoukalos G, Plis Ch, Karadaglis S, Ladopoulos I. Tubal ectopic pregnancy associated with an extraskeletal chondroma of the fallopian tube: case report. Clin Exp Obstet Gynecol 2008;35(1):83-85.

9. Woertler K. Soft tissue masses in the foot and ankle: characteristics on MR Imaging. Semin Musculoskelet Radiol 2005 Sep;9(3):227-242.
10. De Smet L. Posterior interosseous neuropathy due to compression by a soft tissue chondroma of the elbow. Acta Neurol Belg 2005 Jun;105(2):86-88.

11. Onodera K, Xu H, Kimizuka S, Echigo S, Ooya K. Chondroma of the cheek: A case report. Int J Oral Maxillofac Surg 2005 Dec;34(8):924-926.

12. Ryu JH, Park EJ, Kim KH, Kim KJ. A case of congenital soft tissue chondroma. J Dermatol 2005 Mar;32(3):214-216.

13. Ghrea M, Mathieu G, Apoil A, Soubrane P, Dumontier C, Sautet A. Softtissue chondroma of the hand: a case report and analysis of diagnostic procedures for extra-osseous cartilaginous lesions of the hand. Rev Chir Orthop Reparatrice Appar Mot 2003 May;89(3):261-265.

14. Thool AA, Raut WK, Lele VR, Bobhate SK. Fine needle aspiration cytology of soft tissue chondroma. A case report. Acta Cytol 2001 Jan-Feb;45(1):86-88.

15. Anthouli-Anagnostopoulou FA, Papachristou G. Extraskeletal chondroma, a rare soft tissue tumor. Case report. Acta Orthop Belg 2000 Oct;66(4):402404. 